\title{
Breves considerações sobre a mistanásia e o caso do Hospital Universitário Evangélico de Curitiba — PR, Brasil
}

\author{
Gisele Mendes de Carvalho** \\ Rodrigo Róger Saldanha*** \\ Larissa Yukie Couto Munekata***
}

Recibido: junio de 2015

Evaluado: septiembre de 2015

Aprobado: noviembre de 2015

\section{RESUMO}

Não raras vezes, os profissionais da saúde encontram-se limitados ao dar prosseguimento ao tratamento de seus pacientes, devido às condições estruturais dos hospitais públicos, como a quantidade de leitos, qualidade do material hospitalar, qualificação dos próprios profissionais públicos, dentre outros. Neste sentido, o trabalho tem como objetivo apresentar o descaso com os direitos da personalidade e princípios fundamentais no sistema de saúde pública brasileira, apontando a necessidade de políticas públicas para melhoria do - SUS, mais precisamente nas falhas de seu sistema, tomando como exemplo a banalização da vida por uma médica do Hospital Evangélico de Curitiba - PR. Com esse exemplo, buscou-se apresentar também o verdadeiro sentido da eutanásia, e sua evolução na história da humanidade, diferenciando da prática ocorrida no hospital evangélico de Curitiba, que foi apresentado pela mídia no mundo todo como o caso de eutanásia no Brasil. A abordagem do tema é de suma importância para a bioética, pois busca possibilitar uma melhor reflexão sobre o problema e suas possíveis soluções.

Palavras-chave:Direitos Fundamentais, Eutanásia, Saúde Pública, Eutanásia no Brasil, Morte digna.

\footnotetext{
O presente artigo é resultado de uma pesquisa independente desenvolvida pelos Mestrandos Rodrigo Róger Saldanha e Larissa Yukie Couto Munekata, que na graduação iniciaram suas pesquisas em biodireito, bem como no Curso de Mestrado em Ciências Jurídicas da Unicesumar, em Maringá no Paraná, sob orientação da Dra. Gisele Mendes de Carvalho. O artigo objetiva desenvolver novas percepções no biodireito sobre a mistanásia, fazendo uma análise do caso do Hospital Evangélico de Curitiba - Paraná, apresentado pelos meios de comunicação como um dos maiores casos de eutanásia no Brasil, entretanto, verifica-se no projeto uma larga diferença entre a eutanásia terapêutica e o caso do Hospital.

* Mestre em Direito Penal pela Universidade Estadual de Maringá (UEM). Doutora e Pós-Doutora em Direito Penal pela Universidade de Zaragoza, Espanha. Professora Adjunta de Direito Penal na Universidade Estadual de Maringá e no Centro Universitário de Maringá (Unicesumar). Chefe do Departamento de Direito Público da Universidade Estadual de Maringá (UEM). E-mail: giselemendesdecarvalho@yahoo.es

*. Graduado em Direito com Ênfase em Políticas Públicas pela Faculdade Metropolitana de Maringá - FAMMA; Especialista em Ciências Penais pela Universidade Estadual de Maringá - UEM. Pós-graduando em Educação Ambiental pela Universidade Federal de Santa Maria - UFSM. Mestrando em Ciências Jurídicas com ênfase em Direitos da Personalidade - Unicesumar (Bolsa CAPES). E-mail: rodrigorogersaldanha@bol.com.br

...* Graduada em Direito, pelo Centro de Ensino Superior de Maringá (Unicesumar), no Estado do Paraná. Atualmente é pós-graduanda em Ciências Penais junto à Universidade Estadual de Maringá - Paraná (UEM). Mestranda em Ciências Jurídicas pelo Centro de Ensino Superior de Maringá (Unicesumar). E-mail: larissa. munekata@hotmail.com
} 


\title{
Brief considerations mistanásia and Hospital case University of Evangelical Curitiba - PR, Brazil
}

\begin{abstract}
Too often, health professionals are found limited in continuing the treatment of their patients due to structural conditions of public hospitals, as the number of beds, quality of hospital supplies, training of own public professionals, among others. In this sense, the work aims to present the neglect of the rights of personality and fundamental principles in the Brazilian public health system, pointing out the need for public policies to improve the - SUS, more precisely in the failure of its system, taking as example the trivialization of life by a doctor at the Evangelical Hospital in Curitiba - PR. With this example, also sought to present the true meaning of euthanasia, and its evolution in human history, differentiating the practice that took place in the Evangelical Hospital in Curitiba, which was presented by the worldwide media as the euthanasia case in Brazil. The approach to the subject is of paramount importance to bioethics, because aims to enable better reflection on the problem and possible solutions.
\end{abstract}

Key words: Fundamental Rights, Euthanasia, Public Health, Euthanasia in Brazil, Dignified death.

\section{Breves consideraciones sobre la mistanasia y el caso del Hospital Universitario Evangélico de Curitiba, estado de Paraná, Brasil}

\section{RESUMEN}

Con frecuencia, los profesionales de la salud se encuentran limitados a continuar con el tratamiento de sus pacientes, debido a las condiciones estructurales de los hospitales públicos, como la cantidad de camas, la calidad del material hospitalario, la calificación de los propios profesionales públicos, entre otras. En este sentido el artículo tiene como objetivo presentar la negligencia con los derechos de la personalidad y principios fundamentales en el sistema de salud público brasileño, señalando la necesidad de políticas públicas para la mejora del Sistema Único de Salud (SUS, Sistema Único de Saúde en portugués), precisamente en las fallas de su sistema, tomando como ejemplo la banalización de la vida por un médico del Hospital Evangélico de Curitiba, Estado de Paraná. Con este ejemplo se buscó presentar también el verdadero sentido de la eutanasia, y su evolución en la historia de la humanidad, distinguiendo la práctica que se llevó acabo en el Hospital Evangélico de Curitiba, que fue presentado por los medios de comunicación de todo el mundo como el caso de la eutanasia en Brasil. El enfoque del tema es de suma importancia para la bioética, porque tiene como objeto permitir una mejor reflexión sobre el problema y sus posibles soluciones.

Palabras clave: Derechos fundamentales, Eutanasia, salud pública, Eutanasia en Brasil, muerte digna. 


\section{INTRODUCÃO}

Trata-se de breves apontamentos sobre as condições do Sistema Único de Saúde - SUS no Brasil, em especial a qualidade do serviço prestado, sendo desrespeito aos direitos e garantias fundamentais, em especial sobre os direitos à vida e dignidade da pessoa humana, apresentados no primeiro item do trabalho. Utilizou-se de pesquisa bibliográfica, em revista e periódicos especializados, além de jornais e demais noticiários que destacaram o caso exemplificado, fazendo assim, uma análise jurídica, na área do Direito Penal e Constitucional, e da bioética.

Para melhor compreensão do tema, apresenta-se a conceituação das modalidades de eutanásia, e sua evolução histórica, observando suas práticas. Posteriormente, o paradigma criado no entorno do tema, que inviabilizam uma discussão legislativa no país. O tema sempre foi polêmico, mas merece atenção pelas atrocidades realizadas supostamente em nome do progresso da ciência médica.

Posteriormente, destaca-se dessa abordagem o caso do Hospital Universitário Evangélico de Curitiba, principalmente no que diz respeito à imposição e uso do termo eutanásia para destaque da matéria jornalística, que foi divulgado no Brasil e fora dele, como o caso da eutanásia brasileira, entretanto, apresenta-se de forma inequívoca uma disparidade entre a eutanásia terapêutica e o crime de homicídio qualificado que resultou na hodierna investigação, sendo mais que necessária essa diferenciação para a bioética.
Ao final do trabalho, fazendo uma comparação do sistema de saúde pública com a eutanásia social, que afronta os princípios e direitos fundamentais do homem, destaca-se como conclusão, a necessidade de políticas públicas do Estado na Saúde Pública.

\section{DOS DIREITOS, PRINCÍPIOS E GARANTIAS FUNDAMENTAIS}

Os princípios fundamentais são alicerces do sistema jurídico do Estado Democrático de Direito. Não obstante, estão afiançados na Constituição Federal Brasileira de 1988, em seu art. 50, onde apresenta que todos são iguais perante a lei, sem qualquer distinção, além da garantia ao direito à vida, à liberdade, à igualdade, à segurança e à propriedade.

Tais direitos são resultados de uma construção histórica e estão presentes em Tratados Internacionais, nas Constituições dos Estados Nacionais, Decisões Judiciais, dentre outros. São indispensáveis para garantir ao cidadão a busca de uma vida digna com condições mínimas, bem como para ratificar o desenvolvimento da personalidade humana, da autotutela, da proteção contra o alvitre estatal, entre outros. Falar em direitos fundamentais é um aditamento cultural gradativo, pois são anteriores ao ordenamento jurídico e inerentes à própria natureza humana.

Os direitos fundamentais também podem ser chamados de direitos do homem, direitos humanos, ou até direitos públicos subjetivos. Contudo, vale ressaltar que quando ditos fundamentais referem-se às 
normas jurídicas inseridas numa Constituição, sejam subjetivas ou objetivas, que tem por escopo preservar a igualdade, liberdade e a dignidade humana. De acordo com Dimitri Dimoulis (Dimoulis \& Martins, 2012, p.32), os direitos fundamentais atingem tanto as pessoas físicas, quanto jurídicas. Neste ínterim, convém salientar que as normas jurídicas ditas fundamentais não podem ser alteradas - cláusulas pétreas - somente acrescentadas.

Conforme preleciona Alexandre de Moraes, os direitos fundamentais são um conjunto institucionalizado de garantias e direitos, que afiança a autotutela:

\begin{abstract}
A constitucionalização dos direitos humanos fundamentais não significou mera enunciação formal de princípios, mas a plena positivação de direitos, a partir dos quais qualquer indivíduo poderá exigir sua tutela perante o Poder Judiciário para a concretização da democracia. Ressalte-se que a proteção judicial é absolutamente indispensável para tornar efetiva a aplicabilidade e o respeito aos direitos humanos fundamentais previstos na Constituição Federal e no ordenamento jurídico em geral (Moraes, 1998, p. 21).
\end{abstract}

Preponderante destacar também que o conceito de Direito aqui tratado tem raízes no Cristianismo, uma vez que este prega a igualdade dos homens, independentemente da sua origem. Na Idade Média, por exemplo, ainda que existisse uma grande divisão de classes devido a estrutura social, muitos documentos jurídicos retrataram os direitos humanos, visando a limitação do poder do Estado (Moraes, 1998)

Destaca-se também que foi um período em que diversas Constituições aderiram ao modelo principiológico, apresentando em sua formação os princípios fundamentais. A partir de então, passou-se a discutir a preocupação global com a proteção dos direitos da pessoa humana:

Com a Carta da ONU, em 1945, começa-se a limitar o arbítrio discricionário dos Estados sobre seus jurisdicionados. E isso ficou ainda mais evidenciado com a Declaração Universal dos Direitos Humanos, de 1948. Foi um marco histórico para a luta dos direitos e garantias individuais, pois estabeleceu que a promoção de tais direitos deveria ser o critério organizador e humanizador na relação entre governantes e governados. Os direitos humanos tornaram-se, com a Carta, um tema global no mundo pósGuerra. Representam o reconhecimento do ser humano como fim, e não como meio (Casado Filho, 2012, p. 65).

Conforme Norberto Bobbio (1996, p.5657), os direitos do homem têm se modificado na história e, ao fim do século XVIII, era tido como absoluto com as mudanças da sociedade, passou a ter certas limitações, como é o caso do direito à propriedade.

No Brasil, mais precisamente, as mudanças passaram a ocorrer com o processo de redemocratização em 1984, através do 
movimento "diretas já", sendo esse o primeiro passo para a mudança posterior ao período do Governo Militar (1694-1984), que em nome da paz e ordem social, perseguiu, torturou e matou milhares de pessoas.

Assim, inicia-se, também, a busca pelos direitos e garantias fundamentais, que culminou na promulgação da Constituição Federal de 1988, que foi escrita sob as bases da igualdade, da justiça, do pluralismo, da luta contra o preconceito, entre outros valores.

Com a Constituição Federal de 1988, o homem passou a ser visto como titular de direitos, mas em um sentido mais profundo, ou seja, é a Constituição mais democrática que o país já teve, com pilares principiológicos, e conforme o próprio texto que em seu artigo $3^{\circ}$ dispõe que os objetivos do Estado brasileiro consistem em uma sociedade justa, livre e solidária.

Dentre os princípios fundamentais, merece maior reflexão o princípio da dignidade humana, disposto no art. $1^{\circ}$, inciso III, da Constituição Federal de 1988. Esta deve ser respeitada como um princípio máximo, visto que está relacionado ao mínimo existencial para a pessoa, ou seja, não basta apenas o direito à vida, mas esta deve ser interpretada de acordo com a dignidade da pessoa humana.

De toda forma, embora haja direitos formalmente consagrados como fundamentais que não apresentam ligação direta com o princípio da dignidade humana,

\begin{abstract}
é esse princípio que inspira os típicos direitos fundamentais, atendendo à exigência de respeito à vida, à integridade física e íntima de cada ser humano e à segurança. É o princípio da dignidade humana que justifica o postulado da isonomia e que demanda fórmulas de limitação do poder prevenindo o arbítrio e injustiça (Mendes, 2000, p. 45).
\end{abstract}

Neste aspecto, pode-se dizer que todos os outros princípios e direitos fundamentais provêm da dignidade humana, em decorrência da preservação da liberdade, da integridade moral, física e psíquica, entre outros. Vale ressaltar que o homem adquire tal direito com seu nascimento, que o acompanha durante toda vida.

\section{DOS PROCEDIMENTOS DE INTERRUPÇÃO DA VIDA}

Nos termos em destaque por conforme Pessini (Pessini E Barchifontaine, 2007, p. 373), a interrupção da vida com o objetivo de obstar o sofrimento foi encarada por muitos como um princípio de humanidade, tendo como principal protagonista a eutanásia. Deste modo, podemos segmentar a história da eutanásia em três momentos importantes: o primeiro momento é a eutanásia ritualizada; o segundo a eutanásia medicalizada e o terceiro a eutanásia autônoma.

Desta forma, conforme Pessini \& Barchifontaine (2007, p. 373) esse primeiro momento da eutanásia considerada ritualizada é muito próximo do habitual conceito do senso comum de eutanásia, de modo que a morte está fixada 
na história da humanidade, no formato de um ritual de vida, com início no nascimento, passando pela fase adulta, chegando à fase idosa, e posteriormente a morte.

Percebe-se então que foi criado um paradigma sobre a morte, que aos olhos da sociedade esse deveria ser o caminho percorrido por todos os homens, de modo que qualquer ser humano que tenha um desequilíbrio nessa ordem acaba causando uma comoção social.

Na Antiguidade, segundo relatos de Platão, a prática da eutanásia era aceita em recém-nascidos e idosos com anomalias ou simples deficiência, conforme exposto em sua obra "A República". Conforme apresentado por Platão, compreende-se que, nesse período, a eutanásia ritualizada tinha uma aceitação maior na sociedade, onde o chefe da tribo decidia sobre a vida dos anciães enfermos ou recém-nascidos com enfermidades (Platão, 1997, p. 104).

Tem-se, portanto, um breve relato sobre a eugenia, que em breve passar-se-á a analisar nessa pesquisa, pois apesar de o conceito e a nomenclatura terem sido conhecidos muito posteriormente, as características da prática da eugenia permanecem marcadas desde relatos muito antigos.

Logo após, mas ainda nesse período, aproximadamente 600 a.C, com influência das determinações de Numa Pompílio e do Direito espartano, a Lei das XII Tábuas estabelecia ipsis litteris em sua Tábua IV que poderia o pai sacrificar a vida de seu filho, se este nascesse com deformidade, sob o julgamento de sua comunidade (Cretella Júnior, 2009, p. 47).

Ainda nesse período, aproximadamente 500 anos a.C., o conceito de morte foi retratado e conceituado na obra De morbis, parte 5:
Testa enrugada e árida, olhos cavos, nariz saliente, cercado de coloração escura. Têmporas deprimidas, queixo franzido e en- durecido, epiderme seca, lívida e plúmbea, pelos nas narinas e dos cílios cobertos por uma espécie de poeira, de um branco fosco, fisionomia nitidamente contur- bada e irreconhecível (Pessini \& Barchifontaine, 2007, p. 335).

Este conceito de morte perdurou durante a Idade Antiga, Idade Média e Idade Moderna, tendo poucos aprimoramentos, entretanto, devido ao início dos estudos da medicina, teve uma considerável evolução por volta de 1960.

Na antiguidade greco-romana, entendiam os sábios que as enfermidades eram castigos dos deuses aos inocentes, podendo estes serem sacrificados ou não, o Imperador era considerado o primeiro representando dos deuses para os homens, podendo decidir sobre a vida e a morte, que, segundo Ulpiano, regia-se pelo princípio do Princeps legibus solutus est (o príncipe está desobrigado das leis), onde por graça toma suas decisões (Braga Junior, 2007, p. 88).

Tomás de Aquino, na Summa Theologica, 
opõe-se à eutanásia por considerá-la como sendo um atentado à vida humana, sendo uma falta de caridade para consigo, contra a sociedade e contra o direito de Deus sobre a vida, constituindo, assim, uma usurpação do poder divino (Carvalho, G. M., 2002, p. 39). Nesse sentido, com a difusão do Cristianismo Romano, se transferiu o direito de escolha sobre a vida pelo chefe da tribo ou imperador para a divindade, pois segundo a crença, somente Deus tem o direito sobre a vida do homem.

Entretanto, em 476 d. C. foi deposto o último imperador romano, Rômulo Augusto, pelos bárbaros, resultando na queda do Império Romano do Ocidente, sendo um dos fatos mais importantes ocorridos na Idade Antiga, extinguindo-se a figura do príncipe como o representante de Deus, cabendo somente a Igreja se manifestar sobre a divindade e seus ensinamentos (Cataldo, Antonello \& Lopes, 2007, 118).

Assim, por muito tempo a Igreja Católica esteve à frente da sociedade, evangelizando sobre a divindade da vida. O catecismo cristão ensina que a vida pertence a Deus, sendo um direito divino, não podendo o homem dispor desse direito. Durante a Idade Antiga até a Idade Média, devido ao poder que a Igreja Católica Apostólica Romana exercia sobre os grandes reinos, a eutanásia não foi estudada e relatada por muitos autores, pois conforme o catolicismo, a vida humana pertence a Deus, conceito que formulou um paradigma que se reflete até a atualidade.

Com o fim da Idade Média e início da
Idade Moderna, em tempos de reforma protestante (1517), Tomas Morus defendeu a eutanásia em sua obra Utopia (1516), na qual destacou uma sociedade ideal com seres humanos perfeitos; a eutanásia não era aplicada à força, mas o enfermo com doenças consideradas incuráveis era aconselhado a tomar a iniciativa abreviar a própria vida, com uso de veneno ou outras formas. Era, portanto, a realizada eutanásia, pelo fato de o enfermo não ser mais útil à sociedade (Pessini \& Barchifontaine, 2007, p. 374).

Somente após a contrarreforma católica, que tinha o objetivo de frear a expansão da reforma protestantes, por resquícios da santa inquisição, foi que o filósofo Francis Bacon (1561-1626) deu um novo sentido à eutanásia, ao usar pela primeira vez o termo em sua obra História vitae et mortis (1623), observando além do objetivo do fim do sofrimento do enfermo, a forma e procedimento mais eficazes sem dores e nem sofrimento, sendo de responsabilidade do médico cuidar de todas as fases da enfermidade até o último momento de vida; seu conhecimento deveria ser usado na cura, e, também, para minimizar o sofrimento do paciente com enfermidade incurável e em estado terminal, até o findar de sua vida (Pessini E Barchifontaine, 2007, p. 374).

Portanto, durante a Idade Média e a Idade Moderna, tem-se o segundo momento da eutanásia, considerada medicalizada, sendo este o maior momento de sua evolução, quando a eutanásia ritualizada evoluiu devido aos estudos da medicina, iniciados na Grécia antiga, estendendo- 
se ao longo da história, até a Segunda Guerra Mundial.

A eutanásia medicalizada era aplicada aos enfermos em situações consideradas irreversíveis ou chamados de pacientes em fase terminal'. Quando o médico considerava que não havia mais o que fazer aos enfermos doentes, cessava o tratamento e, portanto, só se prolongavam as enfermidades consideradas curáveis (Pessini $\varepsilon$ Barchifontaine, 2007, p. 374).

Por mais que a medicina avançasse nos estudos para abreviar a vida do enfermo terminal, e principalmente constatar que a vida estaria limitada medicamente, existia uma grande resistência devido aos ensinamentos da Igreja Católica e agora protestante.

Na Segunda Guerra Mundial, as recentes afirmações da eutanásia por Francis Bacon influenciaram os pensamentos nazistas, quando o próprio Führer determinou a esterilização de pessoas com enfermidades ou deficiências, como cegueira, loucura, surdez, anormalidade mental entre outras, para hegemonia de uma raça pura, sem doenças, sem defeitos. Assim, em 1933 uma lei com objetivo de prevenir a coletividade dessas enfermidades consideradas hereditárias permitiu o extermínio de milhares de pessoas e, em 1939, cerca de 375 mil pessoas foram mortas (Pessini \& Barchifontaine, 2007, p. 376). O conceito de morte, baseando-se em

Considera-se fase terminal, aquela que, na evolução da doença é incurável ou sem condições de ter prolongada a sobrevivência do doente, apesar das disponibilidades dos recursos, um processo de morte inevitável. parada cardiorrespiratória, evoluiu até a década de 1960, o que hoje não mais representa a morte, graças ao avanço da tecnologia investida na medicina (Bernard, 1997).

Assim, destaca-se sobre os avanços tecnológicos que: "[...] tecnologias médicas de cuidado intensivo permitiram um estudo mais aprofundado do processo de morrer. O processo de morrer pode ser observado em uma graduação que chega à observação de nível celular" (Lothar \& Wondracck, 2006, p. 89).

Luiz Antônio Bento (2008, p. 162) questiona em sua obra, de acordo com a medicina, quando uma pessoa pode ser considerada morta, referindo-se a análise biológica; já que houve um avanço da ciência e tecnologia que proporcionam exames mais exatos do corpo humano. Os sinais vitais, hoje, são diferentes dos verificados há tempos. Eram levadas em consideração, para se diagnosticar uma morte, a parada respiratória e parada cardíaca. Já hoje, o diagnóstico parte do exame do eletroencefalograma, que irá verificar os estímulos cerebrais, considerando morte, a inércia de vibrações do cérebro.

\subsection{0 paradigma da eutanásia na contempora- neidade}

Surge então, o terceiro momento da eutanásia, a autônoma, caracterizada quando o próprio paciente toma sua decisão sobre sua vida e decidi sobre práticas como eutanásia, distanásia, ortotanásia, mistanásia, entre outras. Nas outras fases, 
quem decidia sua aplicação, na maioria das vezes, era um terceiro, podendo ser familiares ou os chefes das tribos, fundamentando-se em razões políticas, eugênicas, sociais ou médicas que acabavam por não levar em consideração a vontade do paciente (Pessini $\mathcal{E}$ Barchifontaine, 2007).

Nesse terceiro momento é que se encontram os conflitos diante esse momento de transição entre as liberdades e o paradigma criado durante a história que a eutanásia é uma afronta à crença e que a vida é algo divino, além do mundo do Direito, e não uma simples existência. Falar sobre a morte, tratar sobre a morte não é um dos assuntos mais agradáveis, devido a esse temor criado na humanidade em distanciar-se das coisas que pertencem à divindade e não ao homem.

Hodiernamente, a medicina usufrui cada vez mais da tecnologia, buscando prolongar a vida do homem, mesmo sabendo que muitos dos procedimentos são dolorosos (Pessini, L., 2004, p. 299). Entretanto, essa tecnologia não está ao alcance de toda população, somente de uma pequena parcela da população, que tem acesso a esse tipo de tecnologia.

A principal classificação operada dentro do conceito de eutanásia divide-a em eutanásia libertadora ou terapêutica, eutanásia eugênica ou selecionadora e eutanásia econômica, de acordo com o motivo que impulsiona o agente. Na eutanásia libertadora ou terapêutica, o móvel é humanitário - sua prática se dá por razões solidárias, altruístas ou de compaixão para com o enfermo que padece. Busca- se eliminar o sofrimento do doente, estando a ação frequentemente envolta por uma carga ou tensão emocional de maior ou menor intensidade sobre o autor, que desse modo se libera da mesma (Romeo Casabona, 1994, p. 423).

Assim, tem-se que essa modalidade de eutanásia está inspirada "por um móvel altruísta generoso e compassivo. A piedade vem a ser o motivo determinante da ação eutanásica por parte do agente que, ao testemunhar o intenso sofrimento do enfermo, decide pôr fim à sua existência" (Romero Ocampo, 1986). O objetivo é justamente libertar o paciente de sua agonia, acelerando o momento da morte. Na eutanásia libertadora, portanto, a vítima é normalmente alguém que padece de enfermidade incurável, ou que se enquadra em casos de reversibilidade difícil ou duvidosa (pacientes terminais, ou que sofreram acidentes cujos traumatismos são irrecuperáveis).

De seu turno, a eutanásia engênica ou selecionadora consiste na supressão indolor de pessoas portadoras de deformidades, doenças contagiosas e incuráveis e de recém-nascidos degenerescentes com o objetivo de promover o melhoramento da espécie humana. Visa-se assim a evitar a perpetuação de indivíduos portadores de anomalias genéticas, distúrbios mentais ou criminosos por tendência para que seus males não se propaguem por toda a sociedade. Há uma busca pela pureza da raça humana, ao eliminar-se todo aquele que careça de valor e seja uma carga familiar e social, cuja morte geralmente se produz 


\section{sem pesar² (Romero Ocampo, 1986, p.9)}

2 A prática e a defesa da seleção e da eugenia são seculares. Os brâmanes tinham o costume de matar ou abandonar na selva as crianças que consideravam de má índole. O Código de Manu continha preceitos de caráter eugênico, ao proibir os casamentos entre membros de famílias doentes ou entre indivíduos tomados por doenças fatais. Também Platão pregava a seleção de raças, ao prescrever que ao Estado cumpria selecionar homens e mulheres e promover o casamento daqueles que possuíssem as melhores características, ao mesmo tempo em que deveria evitar ao máximo os enlaces entre sujeitos débeis. Se uns e outros gerassem filhos, porém, haveria que se privilegiar a criação da prole dos primeiros, e não dos últimos (República, Livro V). Em realidade, como reinava nas civilizações primárias a consideração de que o cidadão vivia para o Estado, o valor que se dava à moral e o constante culto que se rendia ao vigor físico induziram à aceitação da prática constante do infanticídio e do abandono de recém-nascidos em Esparta e em Atenas como medida de proteção da sociedade (Romero Ocampo, 1986, p. 6). A eugenia, na atualidade, pode ser entendida como ações dirigidas à melhora genética da comunidade humana ou de uma raça determinada, mediante o estudo e controle da procriação. Pode ser tomada em duas acepções primordiais: eugenia positiva e eugenia negativa. A eugenia positiva visa à otimização das raças e geração de indivíduos com características desejáveis, seja através da seleção de gametas de doadores portadores desses traços ou de pré-embriões gerados a partir destes, nas técnicas de reprodução assistida (inseminação artificial e fertilização in vitro). A eugenia negativa compreende não só a melhoria das espécies através de técnicas de engenharia genética como também a "esterilização de sujeitos geneticamente defeituosos (enfraquecidos psíquica ou fisicamente), bem como a eliminação de préembriões, embriões e fetos que vão se desenvolver e converter em descendência inferior e defeituosa. Constituindo extremo mais radical, a eliminação de seres humanos já nascidos com tendências genéticas qualificadas - ou qualificáveis - como inferiores" (Benítez, 1997, p. 82). É justamente a eugenia negativa que informa a eutanásia selecionadora, posto que são empregados meios extintivos, e não preventivos (eugenia positiva), para a melhoria da raça. Nesse sentido, a eugenia negativa foi também praticada quando dos regimes totalitários do início do século. A esse respeito, aponta-se que "Adolf Hitler foi um grande propulsor das medidas de profilaxia genética. Sua aspiração
Na eutanásia eugênica ou selecionadora, o sujeito passivo não vive uma agonia lenta e cruel, nem está próximo da morte. Ainda quando se tratam de doentes mentais incuráveis, falta o elemento da iminência do momento da morte e a experimentação de constantes e infindáveis sofrimentos por parte da vítima, exatamente o que faria surgir a compaixão móvel do agente na eutanásia libertadora (Romero Ocampo, 1986).

Já a eutanásia econômica consiste na morte de doentes mentais, loucos irrecuperáveis, inválidos e anciãos movida pelo escopo de aliviar a sociedade do peso de pessoas economicamente inúteis. Ao contrário do que sucede com a eutanásia eugênica, o motivo determinante da eutanásia econômica não é egoístico, identificando-se na maioria dos casos com o convencimento da inutilidade do emprego de esforços adicionais no tratamento do enfermo, com a necessidade de se dispor de meios adicionais e extraordinários para

de criar na Alemanha nacional-socialista uma raça ariana, superior a qualquer outra existente sobre a terra e que a governaria no futuro o levou a tomar medidas tão radicais como o extermínio do povo judeu (que eventualmente poderia contaminar sua tão desejada 'estirpe' ariana), que o mesmo qualificava como parasita da organização nacional de outros povos cuja característica típica era reproduzir-se. Seu ódio não se concentrava apenas sobre os judeus, 'antípodas' dos arianos, mas sobre todo enfermo incurável que se achava em constante possibilidade de contaminar os sãos. Era imperativo dentro de seu plano de perpetuação dos mais fortes impedir de qualquer maneira a procriação de seres defeituosos que gerasse uma descendência igualmente defeituosa. E se preciso deveria proceder-se sem piedade alguma ao isolamento dos enfermos crônicos - bárbara medida para o infeliz afetado, mas uma bendição para seus contemporâneos e para a posteridade" (Romero Ocampo, 1986, p. 5-6). 
outros pacientes que possuam melhores prognósticos de recuperação, ou ainda com o desejo de parentes e familiares de desprenderem-se da carga emotiva e econômica que pressupõe a manutenção do paciente sob cuidados intensivos (Romeo Casabona, 1994, 423).

Desde logo, cumpre salientar que configura hipótese legítima de eutanásia tão-somente a eutanásia libertadora, porquanto é a única que atende aos objetivos de causar a boa morte ao enfermo terminal, com vistas a aliviar sua dor, consoante se depreende da própria etimologia do vocábulo. A eutanásia eugênica (entendida aqui a eugenia em seu aspecto negativo) não pode se caracterizar como verdadeira espécie de eutanásia, porque nem a vítima padece de mal incurável ou encontrase na iminência do falecimento, nem o agente é movido por motivos altruísticos e solidários.

Igualmente a modalidade econômica encontra-se excluída do campo conceitual da eutanásia, vez que os objetivos de aliviar gastos excessivos com a manutenção de pacientes terminais ou o propósito de eliminar sujeitos inaptos a promover o desenvolvimento e a prosperidade social não podem sobrepujar o escopo compassivo ou piedoso, móvel do verdadeiro homicídio eutanásico, em que pese também aqui a conduta recair sobre enfermos incuráveis.

Perfilhando esse entendimento, a maioria da doutrina considera como verdadeira eutanásia tão-somente aquela motivada pelo escopo de aliviar os sofrimentos e agruras de enfermos cuja existência já se tornou esvaziada de sentido pela dor. As demais figuras não se amoldam ao conceito de "morte boa"; antes, identificam-se com as condutas homicidas qualificadas por motivo torpe (art.121, §2, I, do Código Penal) (Romeo Casabona, 1994, 423).

Assim, o que se questiona no presente trabalho é a abrangência e eficácia dos tratamentos de saúde disponibilizados pelo Sistema Único de Saúde, não de forma generalizada do sistema, mas sim em suas deficiências, onde o Estado tem dificuldades de manter a nivelação qualitativa de seu atendimento.

Consoante são as lições de Maria Elisa Villas-Bôas:
[...] uma morte miserável, tran- scendendo o contexto médico- hospitalar para atingir aqueles que nem sequer chegam a ter um atendimento médico adequado, por carência social, por falta de condições e de oportunidades econômicas e políticas, que se refletem numa falta de acesso ao judiciário e na deficiente proteção mesmo aos direitos fundamentais a que fazem jus todos os seres humanos, de forma que eles pas- sam a configurar, desde o nasci- mento (Villas-Bôas, 2005, p. 75).

Portanto, considera-se que o termo mistanásia trata-se da eutanásia social, na abordagem do tema por Okçana Rodrigues (2014, p. 108): "A mistanásia não condiciona sua caracterização à ação de abreviar por desligamento de aparelhos, 
injeção letal ou coisa do tipo [...]". Ainda, defende ser uma espécie de eutanásia de um outro viés, e, neste sentido, assegura: "pois a simples e grave ação do descaso, o aumento da angústia do paciente por não ter acesso ou por ter sido deixado à própria sorte, já podem ser causa de uma "morte infeliz".

Gisele Mendes de Carvalho (2001, p. 19) conceitua eutanásia destacando o seu objetivo, que: "[...] é justamente libertar o paciente de sua agonia, acelerando o momento da morte", revelando que o ato de colocar fim à vida do enfermo, está relacionado aos sentimentos de piedade ou compaixão pelo estado lastimável e sofrimento do paciente, antecipando a sua morte.

Destaca-se, portanto, que a eutanásia libertadora carrega o verdadeiro sentido da prática da eutanásia, que é libertar o indivíduo da enfermidade. Assim, dentre as classificações possíveis da eutanásia, tem-se que a eutanásia passiva, também considerada por alguns como ortotanásia, tem apreço pela efetivação da dignidade humana, uma vez que dentro de um campo de ponderação entre o direito à vida e a dignidade humana, opina-se que deva prevalecer esta última, entretanto, devido às precárias condições da saúde pública no Brasil, faz-se necessária uma abordagem sobre a eugenia e sua possível relação com a mistanásia.

\section{DAS POLITIICAS PÚBLICAS APLICADAS À SAÚDE}

As políticas públicas surgiram por volta de 1960, com a necessidade do Estado em analisar ações políticas para compreender dificuldades sociais da época (Rua, 2009, p. 23-24), surgindo assim duas vertentes:

\begin{abstract}
- As dificuldades por que passavam os formuladores de políticas públicas frente à complexidade cada vez maior dos problemas com que se deparavam, fato que os levou paulatinamente a buscar ajuda para a construção de alternativas e propostas para soluções; e

- A atenção dos pesquisadores acadêmicos em ciências sociais (ciência política, economia, sociologia), que progressivamente passaram a trabalhar com questões relacionadas às políticas públicas e procuraram construir e aplicar conhecimentos às soluções de problemas concretos do setor público (Rua, 2009, p. 24).
\end{abstract}

As políticas públicas, então, surgiram com o fim de encontrar soluções para os problemas sociais com a política de governo e o estudo dos problemas sociais, tornando eficaz a forma de administração pública quanto à resolução da problemática social.

Deste modo, sobre políticas públicas, observa-se:
- A análise que tem como objetivo produzir conhecimentos sobre $\mathrm{o}$ processo de elaboração de políti- ca (formulação, implementação e avaliação) em si, revelando assim uma orientação predominante- mente descritiva. Esta categoria corresponde, na literatura anglo- saxã, ao que se conhece como analysis of policy, referindo-se à 
atividade acadêmica visando, basicamente, ao melhor entendimento do processo político; e - A análise destinada a auxiliar os formuladores de política, agregando conhecimento ao processo de elaboração de políticas, envolvendo-se diretamente na tomada de decisões, assumindo um caráter prescritivo ou propositivo. Corresponde na literatura anglo-saxã, ao que se conhece como analysis of policy, referindose à atividade aplicada voltada à solução de problemas sociais (Rua, 2009, p. 25) (destaquei).

As políticas públicas podem ser consideradas como os meios técnicos de governar, fazendo com que seja aprimorada a maneira de administrar, ou seja, o norte para a administração pública, o resultado final do governo, o objetivo positivo através de políticas públicas (Bucci, 2002, p. 253).

Considerando esta necessidade, alinhada com os direitos fundamentais, assevera Okçana Yuri Bueno Rodrigues que:

A fim de que se garantam direitos como o acesso à saúde e a preservação do direito à vida, é preciso que a administração pública estabeleça políticas públicas de promoção humana. [...] Assim, torna-se imperioso que os programas de políticas públicas implementadas pelo Estado sejam minimamente eficazes (Rodrigues, 2014, p. 52 - 53).

Portanto, de forma mais simples, políticas públicas são ações ou projetos de governo para atender a demanda da so- ciedade, resolvendo conflitos e eventuais problemas através de estratégia política (Rua, 2009, p. 20).

Verifica-se, então, que:

O reconhecimento de um problema, por si só, não garante a ação do governo por meio de uma política pública: é necessário um contexto favorável. A junção entre problema, solução e decisão para o encaminhamento de uma política seguem, assim, uma lógica sistêmica e contingente (Lunelli, 2010, p. 46).

Alguns projetos do Governo Federal são considerados políticas públicas, pois atendem a necessidade da população, conforme cita Maria das Graças Rua: "[...] a reforma agrária, o Sistema Único de Saúde, o financiamento da educação superior ou a adoção de mecanismos de transferência de rendas são políticas públicas" (Rua, 2009, p. 20).

Não podemos confundir políticas públicas com atividades coletivas, pois às vezes o objetivo de ambos é o mesmo, porém, uma deriva da iniciativa privada e outra da administração pública. Tem-se, como exemplo, o projeto bolsa família, que é considerado parte de uma política pública que tem como objetivo erradicar a fome e a miséria e existem projetos de associações, ONGs, empresas com o mesmo objetivo, porém, não são consideradas políticas públicas, pelo simples fato de que políticas públicas são realizadas pelo Estado, tem caráter público (Rua, 2009, p. 20). 
Assim, é o entendimento que "o aspecto funcional inovador de qualquer modelo de estruturação de poder político caberá justamente às políticas públicas" (Rua, 2009, p. 21).

Definem-se, então, políticas públicas como "programas de ação governamental visando a coordenar os meios à disposição do Estado e as atividades privadas, para a realização de objetivos socialmente relevantes e politicamente determinados" (Bucci, 2002, p. 241).

É preponderante que haja a interação entre o Direito e as políticas públicas, tendo em vista que hoje esta predominando os direitos sociais, os direitos difusos de defesa da sociedade e do indivíduo como pessoa, defesa de princípios e entre outros (Bucci, 2002, p. 241).

Assim, verifica-se que: As políticas públicas têm sido criadas como resposta do Estado às demandas que emergem da sociedade e do seu próprio interior, sendo expressão do compromisso público de atuação numa determinada área a longo prazo (Cunha E Cunha, 2002, p. 12).

Por volta da década de 80 , o Brasil passou por mudanças, devido à necessidade de uma nova estratégia de governar a nação, com isso surgiu a ideia de uma democratização do regime que já estava constituído, ocasionando novas formas de pensamento sobre o País e, a partir daí, uma Assembleia Nacional Constituinte que teve como objetivo nortear a democracia do país, com uma legislação voltada para os direitos sociais, que ressaltavam para o estado o dever de estabelecer esses direitos através de políticas públicas (Cunha \& Cunha, 2002, p. 12).

Após a promulgação da Constituição Federal de 1988, essa década ficou marcada pelas políticas voltadas à área trabalhista, como, por exemplo, reivindicação de salários, direito de greve, direitos trabalhistas essenciais, entre outros (Cunha \& Cunha, 2002, p. 14).

Quanto à aplicação de políticas públicas, Maria Paula Dallari Bucci (2002, p. 249) cita que "quanto mais se conhece o objeto da política pública, maior é a possibilidade de efetividade de um programa de ação governamental [...]" e, ainda, complementa que: "[...] Isso é verdadeiro especialmente no campo dos direitos sociais, como saúde, educação e previdência [...]".

Em relação às políticas públicas na área da saúde, no ano de 1923, surgiram, no Brasil, as caixas de aposentadorias e pensão, que eram administradas pelas empresas fazendo com que seus funcionários tivessem, também, ao atendimento de saúde e medicamentos (Paulus Júnior, $\varepsilon$ Cordoni Júnior, 2011, dezembro).

No ano de 1930, o governo criou o Ministério da Educação e da Saúde, visando melhoria e segurança de saúde para o indivíduo. Somente em 1966, surgiu o INPS - Instituto Nacional de Previdência Social, tornando-se o "portão de entrada" para acesso dos trabalhadores a atendimentos de saúde (Paulus Júnior, \& Cordoni Júnior, 2011, dezembro). 
Devido a todo esse contesto de manifestação social, no ano de 1977, o Governo Federal instituiu pela Lei n. 6.439/77 o SINPAS - Sistema Nacional de Previdência e Assistência Social, assim proporcionando uma maior abrangência da Previdência Social (Paulus Júnior, \& Cordoni Júnior, 2011, dezembro).

Pode-se dizer, então, que as políticas públicas são o resultado de uma manifestação positiva da sociedade, uma manifestação que reivindica suas necessidades, e por meio de projetos sociais, tendem a amenizar e, muitas das vezes, resolver os problemas sociais.

Dessa forma, as políticas públicas são as ferramentas necessárias para a obra da administração pública que pretende não somente ouvir a sociedade, mas trabalhar de acordo com seus ideais.

\section{BREVES CONSIDERACOCES SOBRE O CASO DO HOSPITAL UNIVERSITÁRIO EVANGÉLICO DE CURITIBA, PR - BRASIL.}

\begin{abstract}
Médica acusada de praticar eutanásia em UTI de Curitiba é indiciada. Segundo as investigações, Virgínia Helena escolhia principalmente doentes internados pelo SUS (Lomba, 2013, fevereiro).
\end{abstract}

Foi usando o termo "eutanásia" que a esmagadora mídia tratou o caso do Hospital Universitário Evangélico de Curitiba, considerado um dos mais importantes hospitais do Paraná. Protagonista do repugnante caso, a médica Virgínia Helena Soares e Sousa estampou a capa dos principais jornais e revistas do mundo, como suspeita de praticar eutanásia:

- THE TIMES - A Brazilian doctor being investigated in 300 potential murder cases "wanted to play God", according to relatives of one of her alleged victims (Treichel, 2013, março 29).

- CNN - Dr. Death? Brazilian doctor killed 7 patients to free up hospital beds, police say (Birol, 2014).

Assim, a Dra. Virgínia foi presa na data de 19 de fevereiro de 2013, pois conforme investigação policial, ela e mais sete pessoas foram acusadas pelo crime de homicídio com duas qualificações, e crime de formação de quadrilha, tipificado à época (Guedes, 2015, março 20).

Conforme reportagem da Revista Veja, em um relatório enviado ao Ministério Público, com datas entre janeiro de 2006 e fevereiro de 2013, foram assinadas 346 prescrições pela médica, sendo que 317 pacientes morreram no dia que receberam a medicação pela Dra. Virgínia, ou seja, 91,6\% dos que receberam a medicação tiveram óbito. Em comparativo com outros médicos da mesma unidade que a Dra. Virgínia atuava, verificaram-se 128 prescrições, e 17 mortes, ou seja, 13,2\% de óbitos (Leitão, 2013, abril). Dessas considerações, é imperioso destacar que na presente pesquisa, objetiva-se apenas discutir o uso e imposição midiática em usar equivocadamente o termo eutanásia, e apresentar a disparidade com a realidade jurídica, que no caso em comento, 
é longínqua da etimologia da palavra eutanásia.

De acordo com o que fora apresentado, a eutanásia, em sua origem, tem como objetivo uma morte libertadora, ou seja, uma morte com o objetivo de livrar o enfermo do sofrimento desnecessário, quando indiscutível a irreversibilidade da enfermidade que o conduz ao fim da vida.

No caso do Hospital Evangélico, a suspeita é de que a Dra. Virgínia tenha praticado homicídio qualificado, e não a prática da eutanásia, pois não tinha como objetivo abreviar a vida de pacientes terminais, já que existem casos em que os pacientes sequer eram considerados terminais, como é o caso do paciente Ivo Spitzner destacado na reportagem do Fantástico:

Um dos casos que mais chamaram a atenção da polícia é de um paciente do SUS, de 67 anos, que chegou ao hospital se queixando de dores num dos dedos dos pés. [...] Ele passou por uma cirurgia vascular. No dia 24, foi levado para a UTI por causa de complicações. Três dias depois, a médica Virgínia de Souza usa o termo desligar ao se referir ao paciente Ivo (Fantástico, 2013, março 10).

O fato chamou a atenção da polícia, pois nas últimas conversas da médica com funcionários do hospital sobre o paciente, conforme direciona a reportagem, a médica, em tese, estaria preferindo a entrada de pacientes com planos de saúde, em leitos originalmente ocupados por pacientes do SUS:
A última conversa sobre Ivo é na noite de 28 de janeiro. Virgínia pergunta se Ivo "já foi". Virgínia: $O$ Ivo foi? Plantonista: Quem? Virgínia: O Ivo? Plantonista: Ainda não, daqui a pouquinho. Tá quase lá. Virgínia: Tadinho. Plantonista: Tá quase lá.

Em seguida, o plantonista avisa da chegada de um paciente em coma que tem plano de saúde. Virgínia: Que convênio? Plantonista: É PAS. Deve chegar pela manhã. Virgínia: Uhum. Plantonista: Não. Agora. Virgínia: Então você tem que ir com o Ivo. A médica nega que levasse alguma vantagem ao trocar um paciente do SUS por um paciente de convênio (Fantástico, 2013, março 10). destacamos

Após isso, conforme prontuário médico, na manhã o paciente Ivo Spitzner recebeu o anestésico Diprivan, seguido do sedativo Fentanil e duas ampolas de Pavulon. Após aproximadamente 50 minutos, mais precisamente às 10 horas e 30 minutos, o paciente veio a óbito (Fantástico, 2013, março 10).

Considerado essas características, na hipótese de a médica realmente ter abreviado a vida do paciente conforme apresentado pela investigação, não estaríamos diante de uma eutanásia ativa, uma vez que o paciente não manifestou vontade, e também pelo fato, em tese, de ele não ser um paciente terminal ou portador de enfermidade irreversível.

Cumpre destacar também, no que diz respeito à manifestação de vontade 
do enfermo, que a eutanásia pode ser subdividida em três formas, a primeira chamada voluntária, quando o enfermo manifesta sua vontade pela prática da eutanásia, a segunda chamada não-voluntária, quando está impossibilitado de manifestar sua vontade devido ao quadro álgico da doença, e a involuntária, onde o paciente não deseja a abreviação da vida, entretanto, sua vontade não é respeitada (Namba, 2009, p. 172).

Tem-se, portanto, uma diferenciação da vontade do paciente em relação à prática da eutanásia, sendo indiscutível que na forma involuntária, estar-se-ia diante de um homicídio, e dependendo das caraterísticas da modalidade não-voluntária, seria mesmo um homicídio qualificado, caso o paciente depositasse confiança no profissional de saúde, com expectativa de melhora, e tem sua vida abreviada em momento que impossibilite sua defesa e por razões exclusivamente econômicas.

Considerando todo o exposto, defende-se que no caso do Hospital Evangélico de Curitiba, está-se diante de um homicídio duplamente qualificado ao invés de eutanásia, fundamentando-se pelo motivo torpe e sem chances de defesa às vítimas, tipificados no art. 121, $\S 2^{\circ}$, I e IV do Código Penal, além do crime de formação de quadrilha, assim previsto no tempo da consumação do delito (art. 288, CP) ${ }^{3}$.

No que diz respeito ao motivo torpe, destacam-se as lições de Luiz Regis Prado:

Hodiernamente, o crime de formação de quadrilha deu lugar ao delito de associação criminosa (art. 288, Código Penal Brasileiro).
Torpe é o motivo abjeto, indigno e desprezível, que repugna ao mais elementar sentimento ético. O motivo torpe provoca acentuada repulsão, sobretudo pela ausência de sensibilidade do executor [...] (Prado, Carvalho \& Carvalho, 2014, p. 638).

Em relação à ação que impossibilitou a defesa da vítima, Cezar Roberto Bitencourt (2009, p. 139) assevera que: "a surpresa constitui um ataque inesperado, imprevisto e imprevisível; além do procedimento inesperado, é necessário que a vítima não tenha razão para esperar ou suspeitar da agressão". Destaca-se, portanto, que a vítima sequer espera ou suspeita a prática de um delito, pois no presenta caso, quando o paciente deposita confiança no profissional, tem a expectativa de melhoras. Depreende-se ainda de suas lições que: "Não basta que a agressão seja inesperada; é necessário que o agressor atue com dissimulação, procurando, com sua ação repentina, dificultar ou impossibilitar a defesa da vítima".

Portanto, conforme já apresentado, não há qualquer similaridade entre o crime de homicídio qualificado com a eutanásia, sendo a única e simples semelhança entre eles a existência de um paciente, e sequer eram todos eles considerados terminais.

Denota-se uma radiante diferença do crime praticado com a eutanásia, que em seu sentido original, busca abreviar a vida do enfermo e livrá-lo de um sofrimento desnecessário e irreversível, sendo assim, o caso apresenta-se muito mais próximo da eutanásia social ou mistanásia, não 
somente tomando como base exclusivamente o caso do Hospital Universitário Evangélico, mas de boa parte dos hospitais que atendem o Sistema Único de Saúde no Brasil.

Tecnicamente, a prática ocorrida no Hospital de Curitiba poderia enquadrarse não como um homicídio privilegiado, mas sim como um homicídio qualificado (art. $121, \S 2^{\circ}, \mathrm{CP}$ ), seja pela asfixia, que é meio cruel de execução desse delito (inciso III), seja pelo fato de as vítimas terem sua defesa dificultada ou diminuída, já que tratava-se de enfermos (inciso IV) ${ }^{4}$. Demais disso, fica evidente que, sendo comprovado que os crimes se deram não apenas em razão da carência de leitos reinante no Hospital, como também por escusos interesses econômicos dos autores, que pretendiam substituir os pacientes do Sistema Único de Saúde pelos que tinham planos de saúde, o motivo também poderia ser torpe (inciso I), o que igualmente qualificaria esta prática, tornando os homicídios triplamente qualificados.

\footnotetext{
4 Art. 121, $2^{\circ}$ (Homicídio Qualificado) Se o homicídio é cometido: I - mediante paga ou promessa de recompensa, ou por outro motivo torpe; II - por motivo fútil; III - com emprego de veneno, fogo, explosivo, asfixia, tortura ou outro meio insidioso ou cruel, ou de que possa resultar perigo comum; IV - à traição, de emboscada, ou mediante dissimulação ou outro recurso que dificulte ou torne impossível a defesa do ofendido; V - para assegurar a execução, a ocultação, a impunidade ou vantagem de outro crime; Feminicídio VI - contra a mulher por razões da condição de sexo feminino; VII - contra autoridade ou agente descrito nos arts.142 e 144 da Constituição Federal, integrantes do sistema prisional e da Força Nacional de Segurança Pública, no exercício da função ou em decorrência dela, ou contra seu cônjuge, companheiro ou parente consanguíneo até terceiro grau, em razão dessa condição.
}

\section{CONCLUSÕES}

Conclui-se, na presente pesquisa, ser indubitável o dever do Estado de garantir os direitos fundamentais do homem, em especial a dignidade da pessoa humana, considerada a essência do ser humano, o mais profundo sentido da existência humana, que justifica o sentido dos outros direitos a serem garantidos, de modo que um direito sem garantia de dignidade humana - ex., direito à vida -, não pode ser considerado protegido.

Assim, seguida da devida conceituação da eutanásia social e eugenia, emergem-se parâmetros suficientes para trilhar as características da saúde pública nos casos em que o Estado é omisso, considerando com isso a existência de vestígios de uma eutanásia social (mistanásia), uma vez que a omissão, ou a falta de condições mínimas de saúde, resulta em afronta à dignidade da pessoa humana e demais direitos e garantias fundamentais. Ademais, dentre as diversas definições das modalidades de eutanásia, destacou-se a eutanásia passiva, também apresentada como ortotanásia por alguns, pois na ponderação entre o direito à vida e a dignidade da pessoa humana, considerase a prevalência da dignidade da pessoa humana, e sempre que possível, deve prevalecer a autonomia da vontade do enfermo.

Em singelas considerações sobre o caso do Hospital Universitário Evangélico de Curitiba - Paraná, destacou-se a tendência da mídia em deturpar o conceito de eutanásia, em seu sentido originário, 
embaralhando a notícia com objetivo de chamar a atenção do telespectador, que hodiernamente acredita ter ocorrido a prática da eutanásia naquela ocasião.

Defende-se, portanto, que apesar da imposição midiática destacar a prática da eutanásia, não há qualquer similaridade com os crimes praticados, pois trata-se de homicídios qualificados, pois em cotejo com o conceito etimológico e sentido primitivo de eutanásia, não se verifica uma morte piedosa ou por súplicas de um enfermo em quadro de irreversibilidade quadro álgico. Assim, em constantes ocasiões de omissão do Estado em garantir políticas publicas de tutela da saúde, da integridade física e psíquica ao paciente atendido pelo SUS, confronta-se a prática da eutanásia social, o que entendemos ser uma inaceitável afronta à dignidade da pessoa humana e seus direitos fundamentais.

\section{REFERÊNCIAS BIBLIOGRÁFICAS}

Benítez, I. F. (1997). Aspectos jurídico-penales de la reproducción asistida y la manipulación genética humana. Madrid: Edersa.

Bento, L. A. (2008). Bioética: Desafios éticos no debate contemporâneo. São Paulo: Paulinas.

Bernard, J. (1997). Esperanças e sabedoria da medicina. São Paulo: Unesp.

Birol, J. (2014). Brazilian doctor killed 7 patients to free up hospital beds, police say. CNN. Extraído em 29 março, 2015 de http://edition. cnn.com/2013/03/28/world/americas/brazildoctor-deaths/

Bitencourt, C. R. (2009). Código Penal Comentado. (5 Ed.). São Paulo: Saraiva.
Bobbio, N. (1996). Igualdade e Liberdade. (C. N. Coutinho, Trad.). Rio de Janeiro: Ediouro.

Braga Junior, M. (2007). Michel Foucault: A legitimidade e os Corpos Políticos. São Paulo: Minha Editora.

Brasil. Constituição (1988). Constituição [da] República Federativa do Brasil. Brasília, DF: Senado.

Bucci, M. P. D. (2002). Direito administrativo e políticas públicas. São Paulo: Saraiva.

Carvalho, G. M. de. (2001). Aspectos jurídicos-penais da eutanásia. São Paulo: IBCCRIM.

Carvalho, G. M. de. (2002). Alguns aspectos da disciplina jurídica da eutanásia no Direito Penal brasileiro. Revista dos Tribunais, 798, 478-502.

Casado Filho, N. (2012). Direitos Humanos e Fundamentais. Coleção Saberes do Direito. v. 57. São Paulo: Saraiva.

Cataldo Neto, A., Antonello, I. E Lopes, M. H. I. (2007). O Estudante de Medicina e o Paciente: uma aproximação à prática médica. ( $2^{\mathrm{a}}$ Ed). Porto Alegre: EDIPUCRS.

Cretella Júnior, J. (2009). Curso de Direito Romano. ( $31^{\text {a }}$ Ed.). São Paulo: Forense.

Cunha, E. de P. E Cunha, E. S. M. (2002). Políticas públicas e sociais. In: A. Carvalho \& F. Sales (Eds.). Políticas Públicas (pp. 11-26). Belo Horizonte: UFMG/Proex.

Dimoulis, D. E Martins, L. (2012). Teoria Geral dos Direitos Fundamentais. (4ª Ed.). São Paulo: Atlas.

Fantástico. (2013, Março 10). "Fui colocada como um demônio", diz médica acusa de matar pacientes. Extraído em 26 março, 2015 de http:// gl.globo.com/fantastico/noticia/2013/03/fuicolocada-como-um-demonio-diz-medicaacusada-matar-pacientes.html

Guedes, E. (2015, Março 20). Por unanimidade, TJPR decide que Virgínia responderá em liberdade. 
Extraído em 28 março, 2015 de http:// www.bemparana.com.br/noticia/311042/ por-unanimidade-tipr-decide-que-virginiarespondera-em-liberdade

Leitão, L. (2013, Abril). A receita da morte na UTI: 346 prescrições, 317 mortes imediatas. Revista Veja Online. Extraído em 27 março, 2015 de http://veja.abril.com.br/noticia/ brasil/a-receita-da-morte-na-uti-346prescricoes-317-mortes-imediatas

Lomba, L. (2013, Fevereiro). Médica Acusada de Praticar Eutanásia. Extraído em 28 março, 2015 de http://oglobo.globo.com/brasil/medicaacusada-de-praticar-eutanasia-em-uti-decuritiba-indiciada-7633340\#ixzz3ViNGDDHR

Lothar, C. H. E Wondracck, K. H. K. (2006). Bioética: avanços e dilemas numa ótica interdisciplinar do início ao crepúsculo da vida - esperanças e temores. São Leopoldo, Rio Grande do Sul: Sidonal.

Lunelli, C. A. (2010). Direito, Ambiente e políticas públicas. Curitiba: Juruá.

Mendes, G. F. (2000). Hermenêutica Constitucional e Direitos Fundamentais. Brasília: Brasília Jurídica.

Moraes, A. de. (1998). Direitos Humanos Fundamentais. São Paulo: Atlas.

Namba, E. T. (2009). Manual de bioética e biodireito. São Paulo: Atlas.

Paulus Júnior, A. E Cordoni Júnior, L. (2011, Dezembro). Políticas Públicas de Saúde no Brasil. Revista Espaço para a Saúde, Volumen 8, (Número 1), pp. 13-19, dezembro 2006. Extraído em 08 novembro, 2014 de http:// www.ccs.uel.br/espacoparasaude/v8nl/ v8n1_artigo 3.pdf
Pessini, L. E Barchifontaine, C. de P. de. (2007). Problemas atuais da bioética. (8 ${ }^{\mathrm{a}}$ Ed.). São Paulo: Edições Loyola e Centro Universitário São Camilo.

Pessini, L. (2004). Eutanásia: por que abreviar a vida? São Paulo: Centro Universitário São Camilo.

Platão. (1997). A República. (E. Corvisieri, Trad.) São Paulo: Nova Cultura.

Prado, L. R., Carvalho, É. M. de E Carvalho, G. M. de. (2014). Curso de Direito Penal Brasileiro. (13. Ed.). São Paulo: Editora Revista dos Tribunais.

Rodrigues, O. Y. B. (2014). Pacientes Terminais: direitos da personalidade e atuação estatal. Birigui, São Paulo: Boreal Editora.

Romeo Casabona, C. M. (1994). El Derecho y la bioética ante los límites de la vida humana. Madrid: Centro de Estudios Ramón Areces.

Romero Ocampo, G. (1986). La Eutanasia. Bogotá: Pontificia Universidad Javeriana.

Rua, M. das G. (2009). Políticas Públicas. Florianópolis: Universidade Federal de Santa Catarina UFSC.

Treichel, M. (2013, Março 29). Doctor with 'God complex' faces inquiry into 300 deaths. THE TIMES. Extraído em 29 março, 2015 de http://www.thetimes.co.uk/tto/news/world/ americas/article3725050.ece

Villas-Bôas, M. E. (2005). Da Eutanásia ao Prolongamento Artificial. (1 ${ }^{a}$ Ed.). São Paulo: Editora Forense. 